\title{
A novel reverse transcriptase-polymerase chain reaction based-liquid hybridisation (RT-PCR-LH) assay for early diagnosis of dengue infection
}

\author{
Maya B Gunesekera ${ }^{1}$, Menaka D Hapugoda ${ }^{2}$, S Gunasena ${ }^{3}$, S A S C Subasinghe ${ }^{2}$, K B A T Bandara ${ }^{2}$, Baldip K Khan ${ }^{4}$ and \\ W Abeyewickreme ${ }^{2}$
}

(Index words: Dengue, reverse transcriptase, PCR, liquid hybridisation, IgM-ELISA,HAI)

\begin{abstract}
Background Early definitive laboratory diagnosis of dengue is difficult with the tests in routine use at present. Objective To develop a reverse transcriptase-polymerase chain reaction based liquid hybridisation (RT-PCR-LH) technique for the rapid and early diagnosis of dengue.

Research design RT-PCR products of the NS3 gene of dengue virus prototypes and of a few positive sera for dengue virus by culture, were allowed to hybridise in liquid phase with a mixture of dengue specific radiolabelled oligonucleotides. The products were separated by PAGE and visualised by autoradiography. 78 suspected dengue sera were also tested by RT-PCR-LH method, and by IgMELISA and HAI tests, for comparison.

Results Two DNA bands ( $\cong 470 \mathrm{bp}$ and $\cong 455 \mathrm{bp}$ ) specific to dengue virus, were observed. RT-PCR-LH assay takes only $24 \mathrm{~h}$. Of the 78 suspected dengue acute sera tested, $45 / 78$ were positive by RT-PCR-LH, $31 / 78$ were positive by IgM-ELISA, and $14 / 78$ had a HAI titre $\geq 2560$. Duration of fever was known in 72 cases, and infection was detected by RT-PCR-LH in $11 / 22$ of cases with $<5$ d fever and by IgM-ELISA in $1 / 22$. In cases with 5 to $15 \mathrm{~d}$ fever RT-PCRLH and IgM-ELISA/HAI titre $\geq 2560$ detected infection in $30 / 50$ and $27 / 50$ respectively. The 10 sera which were negative by RT-PCR-LH, but were positive by either IgM-ELISA or HAI titre $\geq 2560$ were all $>5 \mathrm{~d}$ fever cases. RT-PCR-LH together with IgM-ELISA were capable of detecting dengue infection in $56 / 78$ of the suspected cases.
\end{abstract}

Conclusion RT-PCR-LH assay developed in this study appears to have an advantage over other diagnostic techniques for the early detection of dengue.

\section{Introduction}

Dengue virus infection may cause dengue haemorrhagic fever (DHF) and dengue shock syndrome (DSS). In DHF and DSS, prompt treatment with blood products and adequate fluid administration can prevent the occurrence of spontaneous bleeding or irreversible shock. Early diagnosis of infection would help in proper monitoring of the disease, admission of patients to hospital when necessary, and reducing the case fatality rate (1). The methods currently available for laboratory diagnosis of dengue infection are virus isolation from cell culture or mosquito inoculation, the detection of anti-dengue antibodies (IgM or $\mathrm{IgG}$ ) and reverse transcriptase-polymerase chain reaction (RT-PCR) based amplification of the viral genome and detection by agarose gel electrophoresis (1). In Sri Lanka the laboratory diagnosis of dengue virus is done by virus isolation using mosquito cell lines (C6/36), detection of antibodies using IgM capture (MAC) ELISA, IgG-ELISA and by haemagglutination inhibition assay (HAI). Virus isolation uses an acute viraemic phase sample for detection but the assay needs 10 to 12 days. Confirmation of current dengue infection by serological assay (IgG ELISA and $\mathrm{HAI}$ ) depends upon a significant rise in specific antibodies between acute phase and convalescent phase serum samples. IgM ELISA assay based on a single serum sample is often used to make a provisional diagnosis, although it is slightly less sensitive than the HAI test. However, a positive IgM ELISA indicates only a recent dengue infection, not necessarily that the infection is current (1). RT-PCR based techniques are currently not used in Sri Lanka for routine diagnosis. The rapid PCR based assays $(2,3,4)$ have the advantage of detecting the virus genome during the acute viraemic phase and they do not require a second sample. Here we report the development of a novel RT-PCR based liquid hybridisation (RT-PCRLH) technique for rapid and early diagnosis of dengue infection.

\section{Methods \\ Clinical specimens}

Acute phase blood samples were obtained from 78 patients clinically suspected of having dengue as determined by the WHO criteria, from the North Colombo Teaching Hospital during the period November to December 2000. Blood samples were collected into sterile disposable vials and transported on ice to the laboratory immediately. Serum was separated and stored at $-70^{\circ} \mathrm{C}$ for further use. A convalescent blood sample was also collected from 10

'Department of Chemistry, Faculty of Science, University of Colombo, Colombo $3 ;{ }^{2}$ Department of Parasitology, Faculty of Medicine, University of Kelaniya, Ragama; ${ }^{3}$ Department of Virology, Medical Research Institute, Colombo 8 and ${ }^{4}$ International Atomic Energy Agency, Vienna, Austria. Financial support: International Atomic Energy Authority for Technical Co-operation Grant No. SLR/06/024 and University of Kelaniya, Research Grant No. RP/03/04/06/01/00. (Correspondence: MBG, Telephones + 94 75953412, + 94 75525369, e-mail: biotech@sit.lk. Received i4 July 2001, revised version accepted 2 August 2002. ). 
patients 3 months after the first sample by visiting their homes. These blood samples were also processed as above.

\section{Serological assays}

Acute sera were tested for $\lg \mathrm{M}$ antibodies using a MAC-ELISA commercial kit (MRL diagnostics), and the HAI test (5) adapted to the microtitration system was performed using dengue virus serotype 2 antigen. The available convalescent sera were also tested by the HAI assay.

\section{Dengue virus RNA isolation}

Total RNA was extracted from serum samples as described $(6,7)$ with minor modifications. To $1 \mathrm{ml}$ of lysis buffer (4M guanidine isothiocyanate, $40 \mathrm{mM}$ Tris-HCI pH 6.4, 17 mMEDTA pH 8.1\% Trition X-100), $100 \mu$ l of acid treated, size-fractionated silica (Sigma, USA) and $100 \mu \mathrm{l}$ of serum were added. The suspension was vortexed and allowed to stand at room temperature for $10 \mathrm{~min}$. The sample was centrifuged at $5000 \mathrm{rpm}$ in a microcentrifuge for $5 \mathrm{~s}$ and the pellet was washed twice in $1 \mathrm{ml}$ of washing buffer $(50 \%$ Ethanol, 10mM Tris-HCI pH 7.4, ImM EDTA, 50 mM NacCl) and in $500 \mu \mathrm{l}$ of water. The pellet was resuspended in $20 \mu \mathrm{l}$ of water and incubated at $56^{\circ} \mathrm{C}$ for $8 \mathrm{~min}$, to elute the RNA.The sample was centrifuged at $5000 \mathrm{rpm}$ for $1 \mathrm{~min}$ and $14 \mu \mathrm{l}$ of supernatant was removed (without disrupting the silica pellet) into a fresh tube containing $4 \mathrm{U}$ of RNase inhibitor. A serum sample from a healthy adult was used as a negative control for RNA extractions. A few clinical sera previously identified as dengue virus positive by culture in Aedes egypti C6/36 cell line and immuno-fluorescence antibody test ( 8 ) and stored at $-70^{\circ} \mathrm{C}$ for less than 6 months were used for the development of RT-PCR-LH assay.

\section{RT-PCR assay}

The oligonucleotide primers used for RT-PCR assays were based on the conserved motifs within the NS3 genes of dengue and other flaviviruses (4): A pair of consensus primers designated as DVI and DV3, designed (4) flanking a 470 bp target fragment in dengue virus serotype 2 , was used. The dengue virus RNA was first reverse transcribed using DV3 primer and the product of RT was then PCR amplified using DV1 and DV3 primer pair. All four dengue virus serotypes (DEN 1-4) are detected by this RT-PCR assay.

RT-PCR was performed (7) using a Thermal Cycler (Perkin Elmer 2400 USA), in a single step, in a reaction volume of $50 \mu \mathrm{l}$ containing $10 \mu \mathrm{l}$ of RNA template, 1 X PCR buffer $1.5,1.5 \mathrm{mM} \mathrm{MgC1}^{2}, 1 \mathrm{X}$. Expand reverse transcriptase buffer, $0.2 \mathrm{mM}$ of each dNTP, $2 \mathrm{mM}$ Dithiothreitol, $0.2 \mu \mathrm{M}$ each of DVI and DV3 primers (Isogen, Holland), 10 U RNase inhibitor, $30 \mathrm{U}$ of expand reverse transcriptase (Roche, $\mathrm{GmbH}$ ) and 2.5 U Taq DNA polymerase (Perkin Elmer USA). The RT-PCR program used is as follows: reverse transcription at $50^{\circ} \mathrm{C}$ for $20 \mathrm{~min}$, an initial denaturation at $95^{\circ} \mathrm{C}$ for $1 \mathrm{~min}$ and 35 cycles of PCR, with denaturation at $95^{\circ} \mathrm{C}$ for $30 \mathrm{~s}$ annealing at $50^{\circ} \mathrm{C}$ for $1 \mathrm{~min}$ and extension at $72^{\circ} \mathrm{C}$ for $1 \mathrm{~min}$. A sample without RNA template was used as a negative control for RT-PCR assays. Dengue virus serotype 2 isolated from infected mosquito cell lines (C6/36) was used as a positive control.
The following precautions were taken to avoid the risk of false positives arising from contamination with PCR products: pre- and post-PCR work were physically separated, all PCR reaction mixtures were prepared under a PCR hood, both positive and negative controls were included and aerosol-resistant filter tips were used in all PCR assays.

\section{RT-PCR-AGE analysis}

RT-PCR products $(10 \mu \mathrm{l})$ were analysed by electrophoresis in $1.5 \%$ agarose gels in $1 \mathrm{X}$ TBE buffer containing $0.5 \mu \mathrm{g} / \mathrm{ml}$ ethidium bromide and visualised under a UV transilluminator (9).

\section{RT-PCR-LH analysis}

Preparation of probe: The four dengue serotype-specific oligonucleotides [downstream primer sequences designated as DSP1-4 and designed (7) within the $\approx 470$ bp RTPCR product], 5 picomoles each were end-labelled (9) together in a $25 \mu 1$ reaction volume containing $1 \mathrm{X}$ Polynucleotide kinase buffer, $20 \mathrm{U}$ Polynucleotide kinase (Roche, GmbH), $20 \mu \mathrm{Ci}$ gamma ${ }^{32} \mathrm{P}$ ATP (AmershamPharmacia, UK) at $37^{\circ} \mathrm{C}$ for $1 \mathrm{~h}$. The probe mixture containing the four end-labelled oligonucleotides was purified using Sephadex G-25 Nap-5 columns (Amersham-Pharmacia, UK) essentially according to the manufacturer's instructions, except that the probe was eluted by spun-column procedure (9) using $250 \mu \mathrm{l}$ of TE. A 1: $2(\mathrm{v} / \mathrm{v})$ dilution of probe in TE, was used for the liquid hybridisation.

Liquid hybridisation: Ten microlitres of RT-PCR product was added to $10 \mu \mathrm{l}$ of probe and the mixture was denatured at $95^{\circ} \mathrm{C}$ for 10 minutes and allowed to stand at room temperature $\left(25-30^{\circ} \mathrm{C}\right)$ for $2 \mathrm{~h}$ or overnight for hybridisation of probe with the target DNA. A "probe only" control sample was also prepared in TE. RT-PCR products of the four dengue prototypes (designated as DEN 1-4) which have been prepared from dengue virus infected mosquito cell lines (C6/36), and obtained from Professor V Chow, Singapore National University, were used for the development of RT-PCR-LH assay.

Polyacrylamide gel electrophoresis: The RT-PCR-LH products were separated by $6 \%$ polyacrylamide gel electrophoresis in 1 X TBE buffer (Technical Manual, Promega Corporation, USA). Autoradiography (9) was performed by directly exposing the gel (wrapped in cling film) to Kodak xray film with intensifying screen (Kodak-Biomax) at $-70^{\circ} \mathrm{C}$ for $8 \mathrm{~h}$.

\section{Results}

\section{Development of RT-PCR-LH technique}

The RT-PCR products of dengue prototypes DEN 1,2,3 and 4 (control samples) gave a major band at $\cong 470 \mathrm{bp}$ in $1.5 \%$ agarose gel electrophoresis. A similar band was detected by liquid hybridisation of these RT-PCR products with a probe mixture containing the four dengue serotypespecific oligonucleotides. However, minor differences in size of RT-PCR products were observed between DEN 2 
and the other types during separation by polyacrylamide gel electrophoresis, which gives a higher resolution than AGE for DNA fragments less than 500 bp (Figure 1). The liquid hybridisation assay was tested with the RT-PCR products of 10 dengue virus positive clinical sera that had been confirmed previously by virus isolation in $\mathrm{C} 6 / 36$ cell line and identification by immunofluorescence. An additional lower molecular weight (LM) DNA band of less than 470 bp (approximately $455 \mathrm{bp}$ ) was also detected by RT-PCRLH technique in some samples (Figure 2). Some specimens had only one of the two DNA bands and some had both DNA bands. The negative control samples did not have either of these DNA bands. Therefore, either of the two DNA bands detected by RT-PCR-LH assay was considered positive by RT-PCR-LH assay for diagnosis of dengue infection in clinical specimens.

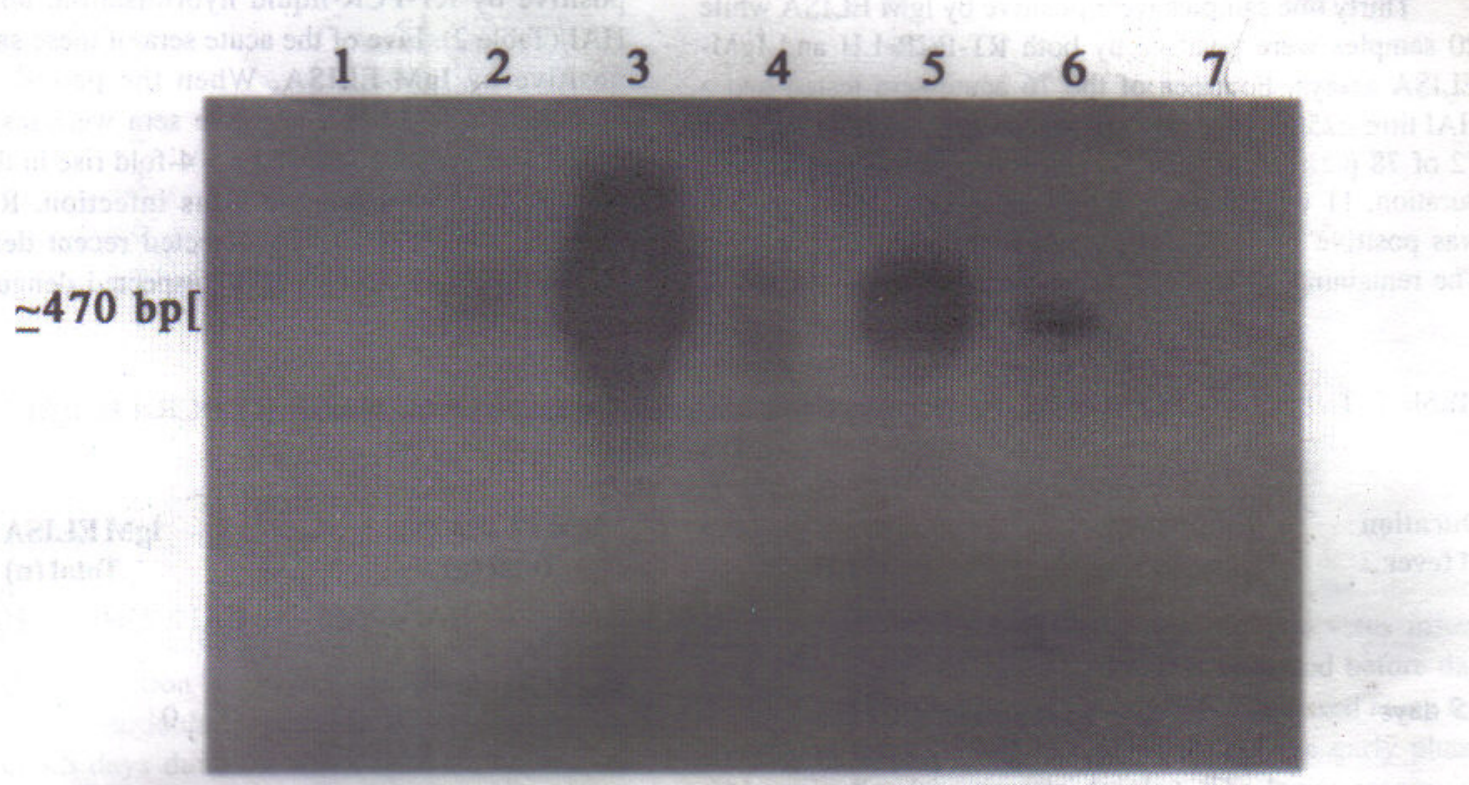

Figure 1. Liquid hybridisation of RT-PCR products of dengue virus prototypes. Lane 1: "Probe only control" for LH assay; Lane 2: Dengue culture positive serum sample; Lanes 3-6: Dengue virus prototypes 1,2,3 and 4 respectively; Lane 7: "Negative control" for RT-PCR; $\simeq 470$ bp: RT-PCR DNA band.

\section{$\begin{array}{llllllllll}1 & 2 & 3 & 4 & 5 & 6 & 7 & 8 & 9 & 10\end{array}$}

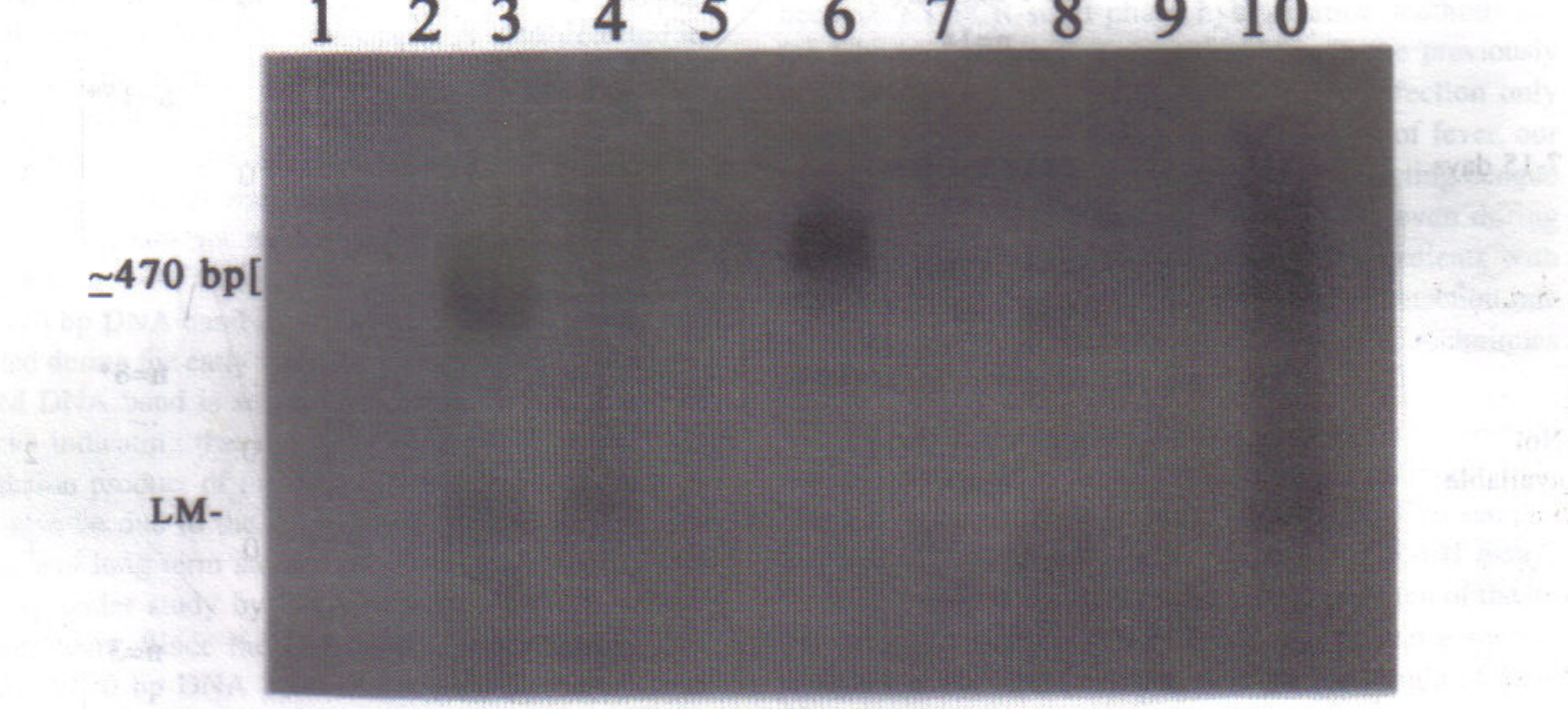

Figure 2. RT-PCR-LH assay of dengue positive clinical sera. Lane 1: "Probe only control" for LH; Lane 2: Normal serum sample; Lanes 3-5 and Lanes 8-10: Dengue culture positive sera; Lane 6: Dengue virus prototype 2; Lane 3: Degue virus prototype 3; $=470$ bp: Expected RT-PCR DNA band; LM: Lower Molecular-weight DNA band. 


\section{Laboratory diagnosis of dengue infection in clinically suspected patients sera}

Of the 78 acute sera tested (Table 1), 45 samples were positive by RT-PCR-LH technique. Only the LM DNA band was detected in the majority $(35 / 45)$ of clinical samples. Two samples had the 470 bp DNA band. Eight samples showed both DNA bands. Only 2 were positive by RTPCR-AGE alone.

Thirty one samples were positive by lgM ELISA while 20 samples were positive by both RT-PCR-LH and IgMELISA assays. Fourteen of the 76 acute sera tested had a HAI titre $\geq 2560$. Data on duration of fever was available for 72 of 78 patients. Of the 22 with fever of less than 5 days duration, 11 were positive by RT-PCR-LH while only one was positive by IgM-ELISA and had a HAI titre $\geq 2560$. The remaining 11 sera that were negative by RT-PCR-LH were also negative by $\operatorname{lgM}$ ELISA and had a HAI titre of less than 2560 . Of the sera collected between 5 and $15 \mathrm{~d}$ of fever, $30 / 50$ were positive by RT-PCR-LH and 27/50 were positive by MAC-ELISA or had a HAI titre $\geq 2560$. Of the 31 samples negative by RT-PCR-LH, 10 were positive by either IgM ELISA or had a HAI titre of $\geq 2560$.

A convalescent sample three months after acute illness was also obtained from 10 of the 45 samples that were positive by RT-PCR-liquid hybridisation, and tested by HAI (Table 2). Five of the acute sera of these samples were positive by IgM-ELISA. When the paired sera of the remaining IgM-ELISA negative sera were tested by HAI assay, three samples showed a $>4$-fold rise in the HAI titre confirming recent dengue virus infection. RT-PCR-LH together with IgM ELISA detected recent dengue infection in $56 / 78$ of the clinically suspected dengue patients.

Table 1. Laboratory diagnosis of dengue infection in clinically suspected acute sera by RT-PCR-LH, IgM-ELISA and HAI assays

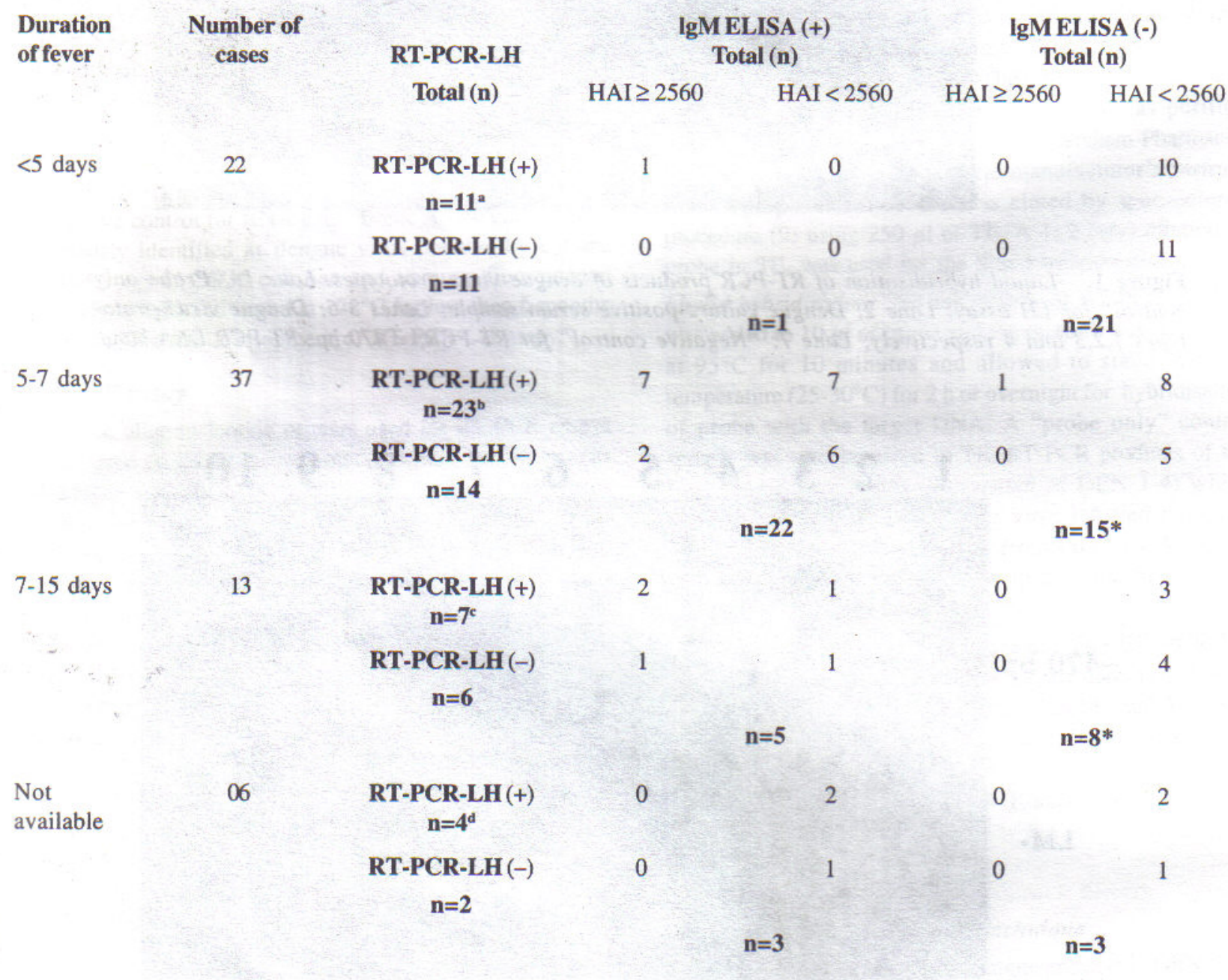

$\mathrm{a} \cong 470$ bp DNA band $=5$ : Two samples also positive by RT-PCR-AGE: LM DNA band $=6$

$\mathrm{b} \cong 470 \mathrm{bp}$ DNA band $=4:$ LM DNA band $=19$

$c \cong 470$ bp DNA band $=0:$ LM DNA band $=7$

$\mathrm{d} \cong 470$ bp DNA band $=1$ : LM DNA band $=3$

* HAI assay not done on one serum sample due to insufficient sample. 
Table 2. Results of IgM-ELISA (acute) and HAI (acute+convalescent) assays of ten cases positive for dengue infection by RT-PCR-LH assay

$\begin{array}{lllll}\text { Case } & \text { Duration of fever } & \text { lgM ELISA (acute) } & \text { HAI (acute) } & \begin{array}{l}\text { HAI } \\ \text { (convalescent) }\end{array} \\ & & & & 320 \\ 12 & 5 & + & \geq 2560 & 320 \\ 13 & 5 & - & \geq 2560 & 160 \\ 28 & 4 & + & 40 & 640 \\ 39 & 5 & + & 320 & \geq 2560 \\ 46 & 7 & - & \geq 2560 & 80 \\ 49 & 4 & - & 160 & 160 \\ 52 & 3 & + & <20 & 220 \\ 61 & 6 & - & 20 & 20 \\ 63 & 4 & - & <20 & 22560 \\ 87 & 4 & & & \end{array}$

\section{Discussion}

An RT-PCH-LH technique has been developed for rapid and early detection of dengue infections. RT-PCRLH is likely to be particularly useful in patients presenting with fever of $\delta$ days duration when IgM antibodies are usually not detectable. In patients with fever of 5 to $14 \mathrm{~d}$ duration, the use of both RT-PCR-LH and IgM-ELISA results in higher detection rate, than with serological assays alone.

The liquid hybridisation assay is performed using a mixture of oligonucleotides which specifically hybridise with dengue virus only. Two hybridising DNA bands ( $\cong 470$ bp + LM DNA band) were detected in dengue virus infected clinical samples. The LM DNA band is also detected in the RT-PCR products of the dengue prototypes as a faint minor band in ethidium bromide stanined agarose gels when a higher amount of the RT-PCR product was loaded into the gel and this band was occasionally detected by liquid hybridisation (data not shown) indicating that both DNA bands can be used for diagnosis by this method. While the $\cong 470$ bp DNA band is usually seen in clinical samples collected during the early viraemic phase ( $<6$ days of fever), the LM DNA band is seen even during the late phase of viraemia indicating that the latter band could be due to a degradation product of the NS3 region of viral genome. It could also be due to the degradation of virus during processing and long term storage of clinical samples. This is presently under study by DNA sequence analysis of RTPCR products. Since the LM band is observed together with the $\cong 470$ bp DNA band in some clinical as well as some prototype samples isolated from cultures, and the fact that dengue serotype specific oligonucleotides were used in the liquid hybridisation assay, it is unlikely that the LM band is due to the presence of any other flavivirus in the sample.
RT-PCR-LH seems to have an advantage over the other techniques in detecting recent dengue virus infection when the acute phase serum was collected before day 5 of fever. This is expected for any RT-PCR based assay for dengue as the viraemia is highest during the early phase and antibodies take time to develop. The lower sensitivity shown by RT-PCR-AGE has been noted previously in comparison with nested PCR assays (3). The nested PCR technique and solid phase hybridisation techniques were not compared with RT-PCR-LH technique in this study. This is because nested PCR is not recommended for routine use due to possible contamination with amplicon when processing a large number of clinical samples $(10,11)$, and because RT-PCR-solid phase hybridisation methods are too laborious for routine use (3). Although the previously described PCR based techniques detected infection only in acute sera collected during the first 5 days of fever, our technique of RT-PCR-LH was capable of detecting dengue viral genome/possible degradation products even during the late phase of viraemia (including a few patients with two weeks of fever) giving an overall higher detection rate of recent infection over the other diagnostic techniques (RT-PCR-AGE, IgM ELISA and HAI).

We were unable to obtain a second serum sample from the entire study population within the optimum time, which is between 14 to 21 days following the first sample, for confirmation of the results of the RT-PCR-LH assays by HAI assay. However, we were able to trace ten of the 45 patients with positive RT-PCR-LH results and a second sample was obtained 3 months after the first. Eight of these 10 patients showed serological evidence of recent dengue infection, as indicated by a positive IgM-ELISA in the acute phase, or a rising titre in the HAI assay, at the follow-up. The delay in obtaining the follow-up sample, and the possibility of not detecting antibodies of some dengue sero- 
types may have reduced the sensitivity of the HAI test in the study which employed only dengue serotype $2 \mathrm{HA}$ antigen.

The RT-PCR-LH assay is a rapid technique with a turnaround time of only 24 hours. We are now making improvements and validating the technique in a larger clinical study, so as to make it available as a non-isotopic routine diagnostic method that would eliminate handling of radioisotopes and the need for special laboratory facilities and training.

\section{Acknowledgements}

We are grateful to Professer N R de Silva, Head, Department of Parasitology, Faculty of Medicine, University of Kelaniya, for her support. We appreciate the support given by Prof. V Chow, Department of Microbiology, Faculty of Medicine, National University of Singapore, and Dr. K Kaul of Evanston Hospital Corporation, USA, for their assistance in RT-PCR assays and liquid hybridisation technique. We thank the Director and the Physicians of The North Colombo Teaching Hospital, Dr. G Colombage (Director) and the technical staff of the Department of Virology, Medical Research Institute, Professor U T Vitarana (University of Sri Jayewardenepura) and Dr. N Withana (WHO, SEARO, India) for their cooperation.

\section{References}

1. World Health Organization. Prevention and control of dengue and dengue haemorrhagic fever. WHO Regional Publication, South East Asia Regional Office (SEARO) 1992: 29: 21-38.

2. Morita K, Tanakara M, Igarashi A, Rapid identification of dengue virus serotypes by using polymerase chain reaction. Journal of Clinical Microbiology 1991; 29: 2107-10.

3. Lanciotti RS, Charles CH, Gubler DJ, Chang GJ, Vorndam AV. Rapid detection and typing of dengue viruses from clinical samples by using reverse transcriptase-polymerase chain reaction. Journal of Clinical Microbiology 1992; 309: 545-51.

4. Chow VTK, Seah CLK, Chan YC. Use of NS3 consensus primers for the polymerase chain reaction amplification and sequencing of dengue viruses and other flaviviruses. Archives of Virology 1993; 133: 157-70.

5. Clark DH, Cassala J. Techniques for haemagglutination and haemagglutination-inhibition with arthropod borne viruses. American Journal of Tropical Medicine and Hygiene 1958; 7: 561-73.

6. Chunge E, Roche, Lefe MF, Barbazan P, Chanteau S. Ultrarapid, simple, sensitive and economical silica method for extraction of dengue viral RNA from clinical specimens and mosquitoes by Reverse Transcriptase Polymerase Chain Reaction. Journal of Medical Virology 1993; 40: 142-5.

7. Seah CLK, Chow VTK, Tan HC, Chan YC. (1995 A). Rapid, single-step RT-PCR typing of dengue viruses using five NS3 gene primers. Journal of Virilogical Methods 1995; 51: 193200.

8. Gubler DJ, Kuno G, Sather GE, Valez M, Oliver A. Mosquito cell cultures and specific monoclonal antibodies in surveillance for dengue viruses. American Journal of Tropical Medicine and Hygiene 1992; 30: 545-51.

9. Sambrook J, Fritsch EF. Maniatis T. Molecular Cloning. New York: Cold Spring Harbor Laboratory Press, USA, 1989.

10. Seah CLK, Chow VTK, Chan YC. Semi-nested PCR using NS3 primers for the detection and typing of dengue viruses in clinical serum specimens. Clinical Diagnostic Virology 1995; 4: $113-20$.

11. Seah CLK, Chow VTK, Chan Y, Doraisingham S. A comparative prospective study of serological, virus isolation and PCR amplification techniques for the laboratory diagnosis of dengue infection. Serodiagnosis and Immunotherapy of Infectious Disease 1995; 7: 55-8. 